\title{
From the conceptual ideation theory on joint-dialogical cognitive activity
}

\author{
Satybaldy M. Jakupov, Aliya A. Tolegenova, Nazirash S. Zhubanazarova, \\ Nurgul K.Toksanbaeva, Maksat S. Jakupov \\ Al-Farabi Kazakh National University, Almaty, Kazakhstan
}

\begin{abstract}
In the article, we are going to consider the possibilities of a conceptual framework of the semantic theory of thinking, which could allow us to develop a concept of joint and dialogical cognitive activity. This paper demonstrates O.K. Tikhomirov's creative influence on the development of cognitive activity psychology. The role of aim-forming in thinking as a process of cognitive activity and genesis of reflection is emphasized. The possibilities of joint and dialogical cognitive activity formation as a result of informative purposes assigned to learners are shown. The role of ethnic prejudices as representations of semantic barriers, during the studying of the virtual mono-ethnic subgroups modeling method (in the conditions of a pilot study of the ethno-psychological phenomena) is considered and is specially allocated. In the present article, the mechanisms of psychotherapeutic influence are also considered and possible intervention programs for an emotional condition are described. Evidences of efficiency of formation and the transformation of personality-semantic education are provided in joint and dialogical counseling, realizing a semantic approach and its development, based on the principles of joint and dialogical cognitive activity.
\end{abstract}

Keywords: semantic theory of thinking, aim forming, joint and dialogical cognitive activity, semantic barriers, ethnic prejudices, semantic educations of the personality, joint and dialogical consultation.

O.K. Tikhomirov was the first to study ideation as a specific forming activity. He initially suggested recording systemic properties of the subject of activity; later on, that predetermined the formation of the conceptual ideation theory (CIT). Two circumstances of utmost importance facilitated the aforementioned process: firstly, the implementation of the method of parallel recording of verbal and non-verbal components of the ideation; and secondly, the employment of chess problems as the object of cognitive activity, which was previously and undeservingly ignored.

In the second half of the 20th century, O.K. Tikhomirov proposed the experimental situation model for studying the ideation during chess problems solving. The interpretative potential of this model was made fully available for comprehension only recently. Here we speak about chess problems referring to a distinctive 
type of so-called interactive tasks which were widely used at that time in social and psychological studies, but were mainly not employed in general psychology. Here we mean not the chess problems by themselves, but their interactive nature, which manifests in the necessity of considering the assumed actions of one's opponent meaning distinctive virtual partner in joint-intellectual activity (more correctly to say, pseudo-individual activity). An interactive chess problem initially determines the special conditions for the generation and development of a specific conceptual field, which later serves as a basis for the intellectual activity of the test subject. In its turn, it is perceived by the observer (experimenter) as an activity which is individual in its nature. Nevertheless, considering interactivity as a peculiarity of the solved task which also is subject-generated, this activity is more likely to be pseudo-individual, meaning that it is actually externally unobservable joint activity.

For the first time ever, the phenomenon of pseudo-individual intellectual activity was studied under the guidance of O.K. Tikhomirov in the 1980's (Jakupov, 1985). These studies were dedicated to the transformation of joint-practical activity into joint-intellectual activity under laboratory conditions and revealed a phenomena of pseudo-joint and pseudo-individual intellectual activity. In the first case, we mean the activity of two individuals which is externally observed as 'joint' interaction; on the other hand, in its own internal meaning and psychological content such activity presents a combination of two individual activities. Pseudo-individual intellectual activity in psychological (internal) context represents 'joint' activity for it depicts all of its components, while externally representing the activity of a single individual. In such a joint activity process, the partner is not the individual himself, but his image, more correctly - a 'virtual subject', being the result of virtual reality modeling by means of special technique of experimental study based on the employment of the subject-generating feature of an interactive task. During this process, an internal 'virtual dialogue' with a 'virtual partner' while solving intellectual tasks shows no less efficiency - at times, concerning certain tasks it is more effective than an 'external dialogue' with the real partner.

The experimental technique, which was developed under the conditions of a real and virtual - hence ceaseless - dialogue with Oleg Konstantinovich, provided not only for the formation of joint intellectual activity but also its controlled dissociation. The following sequence of transformations was experimentally revealed: individual practical actions - joint practical activity - pseudo-joint intellectual activity - joint intellectual activity - pseudo-individual intellectual activity. The stage-by-stage transformation of activities up to the stage of joint intellectual activity is provided by the structure of presented interactive tasks. Such tasks which may be successfully solved with the consideration of the results of a partner's activity, whereas achievement at the joint intellectual activity stage was provided, according to our researches, by forming a 'common fund of conceptual formations' (Jakupov, 1985) in the course of communication; this 'common fund of conceptual formations' was 'disguised' by the 'common fund of information' (Lomov, 1984). The decisive element here was not the contents of the common fund of conceptual formations (CFCF) itself, but the grade of its acceptance and assumption by the partners in the joint activity. The latter evidence determined the difference between psychological structures of pseudo-joint, joint and pseudo-individual intellectual activities. A special series of experiments concerning the stage-by-stage introduc- 
tion of communication deprivation (destruction) for the purpose of controlling the process of assumption of CFCF demonstrated dissociation of pseudo-joint intellectual activity into individual activities in one case and the transformation of joint intellectual activity into the pseudo-individual intellectual activity in another case.

Qualitative distinctiveness of activity, which is pseudo-individual in its form and intellectual in its contents (which manifested better results in comparison with other forms of intellectual activity) is provided by a higher grade of assumption of CFCF by each partner - that substantively widens the individual capabilities of each partner (Jakupov, 1992). In its psychological meaning, the assumption of CFCF by the subject of activity means the intensification of the reflexive mechanisms of joint - dialogical cognitive activity, based on the actualization of the external partner's image during the transfer from an 'external' dialogue to the 'internal' one. In other words, we speak about the construction of a virtual reality model which is composed of virtual subjects and various types of virtual activities with their basic constructional elements being conceptual formations which, in turn, compose the CFCF.

\section{Goal formation as a process of reflection of cognitive activity's genesis}

Studies concerning goal formation under conditions of transition from joint practical activity to the joint intellectual activity, being adequate enough to act as a model for cognitive activity genesis research, allow us to draw our attention to some particular aspects of its procedure. The process of transformation of practical activity of a dyad (complex subject) into the intellectual activity of an individual subject is nothing but formation and development of the subject of cognitive activity, expanded in space - time dimensions. The cognitive activity, while initially determining the subject's activity, is itself the specific result of the process of the "subject-subject-object"kind of interaction.

This approach states the special problem of analysis of the role of communication in the process of transformation of activities which are individual in their forms and practical in their contents into joint in their forms and intellectual in their contents activities. Here, the problem of formation of joint activity appears - and this problem leads us to necessity of interconnection between communication and ideation research. Studies performed under B.F. Lomov's supervision have shown qualitative and quantitative rearrangement of the cognitive processes under conditions of joint activity and communication in comparison with individual activity (Lomov, 1984). Substantial influence of communication on processes of ideation on various levels was described: from acquisition of notions up to solving creative tasks. Role of the basic determinants conditioning the influence of communication on ideation had been played by the common fund of information, specific regulation mechanisms of dynamics of individual cognitive processes, joint strategies for tasks solution and common - group activity style. During this study the sophisticated interconnection of ideation and communication was narrowed down to processes of information accumulation in 'common information fund' and that caused positive influence on the results of joint ideation in individuals.

While disagreeing with such interpretation of interconnection of ideation and communication, we have to emphasize that, for the common fund of information 
to act as an actual thing for each of participants, it is necessary that it is initially presented to all subjects and accepted. This is substantiated by results of experiments of Ya.A. Ponomarev concerning research of creative tasks solution under conditions of communication (Ponomarev, 1981). In this research, the by-product of activity acted as a 'key to solution' of the task only in the process of its comprehension by other participants, while it could be inconsistent and thus useless to the subject solving the task.

Studies performed by A.V. Brushlinsky are considered as continuation of the aforementioned studies and have allowed to reveal the phenomena of 'psychological blindness and deafness', which points out the insufficiency of interconnection of ideation and communication information interpretation (Brushlinsky, 1982). It should be noted that 'the new idea on its own does not upraise the process of ideation of all group members up to common level, that may be achieved only if their contents match or are very close by contents'. Later 'convergence of the contents of partners' ideation proceeds as gradual comprehension of their mutual ideas and their inclusion into the system of connections and relations of each of them'. Nevertheless, such explanation does not reveal the true nature of the 'psychological blindness and deafness'. This contributes to an explanation of the 'gradual comprehension of ideas' in psychological context.

Results of our studies claim that the common information fund which is formed under conditions of joint intellectual activity actually does play role of additional source of the individual's activity - but only in case of its assumption by subjects of activity. This is determined, in its own turn, by actual structure of the personality, its direction and its 'dynamical conceptual system' (Vygotsky, 1982).

Realization of principle of unity of communication and ideation in particular psychological study gains extreme actuality due to research in genesis of cognitive activity. One of means of realization of this principle is research of goal-formation during joint intellectual activity which allows us to reveal interconnections between 'dynamical conceptual systems' and 'common information fund'. This fact in its own turn gave us the possibility to 'throw a methodological bridge' between personal and cognitive components of the subject's cognitive activity and to close up with the origins of personality's cognitive activity under conditions of specially developed experimental - empirical research scheme.

\section{Joint - dialogical cognitive activity in the process of education}

The results of goal formation research in joint intellectual activity allowed us to develop psychological basis of conceptual representation concerning the transformation of the teacher's personality and personalities of students into the joint dialogical cognitive activity in the process of learning (Jakupov, 1992).

The necessity of joint-dialogical cognitive activity (JDCA) modeling under the conditions of experiment is determined by the fact that JDCA is actually a systemic formation, which is formed in the process of learning and which is the actual psychological content of that process. Attempts to study JDCA directly in real learning process, as a rule, lead to dissociation of the whole phenomenon because the JDCA occurs only at a certain level of development of the cognitive activity in the learning process and thus marks the highest possible level of the latter. 
Processual aspect of the cognitive activity has always been the stumbling stone of researchers. Usually they study the results of cognitive activity and not the process itself. That is even harder to achieve considering the joint-dialogical cognitive activity - a psychological phenomenon which may only exist in processual form. Isn't it because of that fact that the majority of methods employed in pedagogy and pedagogic psychology have low 'ecological validity'? Reason is the same for impediments in research of processual aspect of active methods of education, such as social-psychological training which achieves the highest level of cognitive activity - the JDCA - more often than traditional educational techniques.

There is another way of studying cognitive activity which is learnt from general psychology. It involves modeling the researched process in experimental laboratory conditions with the purpose of in-depth research of major psychological laws of appearance and following formation of phenomenon in the real conditions of learning process on the basis of knowledge of such laws. This is the path which is considered enough valid for researching such sophisticated phenomenon as jointdialogical cognitive activity.

In its own turn, the most adequate laboratory model of JDCA is the joint intellectual activity (JIA) which is formed in the process of solution of special experimental tasks by the test subjects. Similarly to the JDCA, intellectual activity presents the highest level of development of problem-solving activity. And as the cognitive activity in real conditions of learning process - especially JDCA - is actually the consequence of transformation of practical activities of the teacher and students, similarly, in laboratory conditions the intellectual activity - especially JIA - is preceded by the practical activity.

In real JDCA the external conditions of joint and dialogical kind are determined by the form of educational goals which are to be realized by the teacher as goals of education and as goals of learning by the students. Both assume that individual-practical teaching activity and the individual-practical learning activity are performed. Internal conditions of JDCA are formed in the process of teachinglearning interaction on the basis of integration of concepts of these activities with following formation of motive for activity which is common in its form and cognitive in its content. The joint cognition is possible only in presence of common cognitive motive, with the highest level of the former being joint intellectual activity.

There is another fact supporting adequacy of laboratory JIA to real JDCA. It is the match of psychological mechanisms in formation of both. JDCA as the highest level of development of cognitive activity in the real educational process and JIA as the highest level of development of intellectual activity in its laboratory model are formed under conditions of communication. And communication in this case is represented by a psychological formation of two forms: firstly, as a condition of formation of joint type of activity, i.e. the transformation of individual activities into the joint activity, secondly, as the condition of transformation of practical actions into the intellectual activity. The keystone of all the mentioned transformations are the processes of goal-formation, motive-formation and concept-formation.

Right along with this problem we note that the topic of workshop in the educational process and its main problems may transform into the goal of joint cognition under certain specific conditions. Nevertheless, the formation of common goal does not readily mean that its achievement by each subject directly provides the 
formation of joint cognitive activity. We need psychological mechanism providing 'connection' of teacher and students activities along with so-called 'docking' and their transformation into the joint-dialogical cognitive activity. Studies have shown that such mechanism is presented by the mutual reconstruction of intermediate cognition goals by the partners, during which the reconstruction of a common goal is performed. The process of its assumption provides the formation of jointdialogical cognitive activity.

Hence, if the process of joint-dialogical cognitive activity formation is possible as a result of assumption by the students of the teacher's cognitive goals, then their mutual reconstruction of intermediate cognition goals and their assumption may be performed during communication. Consequently, the verbal (vocal) means of communication facilitate the process of reconstruction of cognitive goals of the teacher whereas non-verbal communication means (intonation, mimics, gestures) allow to reconstruct teacher's 'motive-goal' relations to the students, therefore providing the reconstructed goals with personal concepts. The latter is of utmost importance as it provides the reconstructed and assumed 'alien' goal with the required entities, thus providing it with activity meaning. In the end, transfer and transformation of concepts during communication of subjects in learning process allows to understand laws and principles of goal formation and motives of joint activity, accounting to which the learning process creates the necessary conditions for jointdialogical cognitive activity formation.

\section{New explanatory possibilities of categorical apparatus of conceptual theory of ideation}

Our studies, dedicated to transformation of joint practical activity into joint intellectual activity under conditions of laboratory experiment revealed a phenomena of pseudo-joint and pseudo-individual intellectual activity. The obtained data allowed us to assume that it is possible to form similar phenomena in other types of activity including ones which initially exclude such possibility, as it seems - more precisely, various laboratory models of individual activities.

Researchers have noted the phenomena connected with distortions of the research results concerning individual activities in laboratory conditions determined by obvious presence of experimenter. The main reason of these phenomena is seen by us as formation of pseudo-individual activity in the research process which evades the experimenter's attention because of its 'pseudo' attribute.

Let us address the scheme of laboratory experiment to clarify our assumptions. Traditionally, experimenter's presence is apparent during the initial stage of preparations for research: giving instructions to the test subjects, etc. Then, during the next phase the experimenter, as a rule, leaves test subject alone with the task, equipment, etc. It is assumed that along with the development of the test subject's individual activity the test subject himself and his activity will be less determined by the experimenter and, later, when the test subject will be totally engaged in performing the task with maximal motivation, the experimenter's influence will be neglected.

From our point of view, it is this neglection (having place nearly in every study of individual activity under laboratory conditions) that creates massive amount of contradictory facts in researches of individual activities of similar types carried 
out by different people. The differences concerning the purity of experiment, while influencing the results of experiment, are not the only factor; rather, it is different duration of communication of an experimenter and a test subject. We assume that prolonged communication between them in the process of accomplishing task in form of 'communication' of test subject with the imaginary experimenter creates the conditions for formation of common fund of conceptual formations. The latter assumption, meaning the solution of experimental task by the test subject with account of proposed opinions and estimates of the experimenter, significantly influences the activity of test subject himself facilitating its transformation from individual activity into pseudo-individual. Although, as we have already noted, the latter one is actually different psychological reality, it is not the only one experimenter is studying in his programmed research. Obviously, that is why he does not recognize its actuality and is perceived as collateral variable distorting the expected results.

Necessity to account for the phenomenon of pseudo-individual activity, which has place nearly in every laboratory experiment (and in certain field experiments, possibly) as a specific factor is marked by the results of research concerning the phenomena of 'over-activeness'. We assume that the bases of phenomena of 'oversituational activeness' (Petrovsky, 1975) and 'intellectual activeness' (Bogoyavlenskaya, 1986) are created by psychological mechanisms similar to the aforementioned.

The over-situational activeness (having the phenomenon of self-denying risk as one of its empirical indicators) has an underlying social factor determined by the dialogical character of the structure of experiment. In this study, the dialogical character of experiment is provided by the factor of threat, presenting the interconnecting component between the experimenter and test subject, thus establishing a possibility to create a common fund of conceptual formations. The test subject participates in the process of creation directly, while the experimenter participates indirectly through the threat factor. Meaning of V.A. Petrovsky's experiments states exactly that the test subject in the process of activity obtains additional activity from the common fund of conceptual formations.

We notice similar psychological mechanisms determining additional activity of subject of activity which could not be explained by actual motives and needs as the basis for phenomenon of 'intellectual activity'. D.B. Bogoyavlenskaya, who firstly experimentally separated and described this phenomenon, sees the intellectual activity 'as certain characteristic of creative ideation' (Bogoyavlenskaya, 1986). While seeing in the act of definition 'highest manifestation of intellectual activity' a problem, author sees its sources in the intellectual initiative which, in turn, depends on the grade of activeness of cognitive activity, cognitive interest, cognitive needs.

We see the possibility of 'drawing' additional activity from the common fund of conceptual formations by the subject as concrete psychological mechanism of subject's additional activity formation. In this case, the common fund of conceptual formations of personality was formed as a result of 'internal dialogue' and communication of test subject with imaginary assumed partner. Namely, these proposed steps of assumed adversary increase the number of degrees of freedom of the test subject's ideation, thus providing creativity of his intellectual activity. We must emphasize that the point of drawing additional activity is in alteration of hierarchical 
system of his conceptual formations by the test subject as a result of comparison with the conceptual formations of assumed partner or chess adversary.

All cases analyzed by us presented the ignoring of social aspect of the interiorization principle, which was understood by L.S. Vygotsky as the transformation of interpsychic into intrapsychic (Vygotsky, 1983). This fact evidences subjectivity of the researchers, which 'locks' them in the framework of subject-subject analysis of the activity. At this time one half of researchers when accidentally meeting the phenomena of formation of additional activeness in the form of pseudo-individual activity under conditions of laboratory modeling of activity are trying to neutralize such as an interference. Other researchers intentionally create experimental conditions for formation of various forms of over-activeness ('over-situational activeness', 'intellectual activeness') and search for the true sources of such either in subject's personality traits or in the features of the object (problem).

We experimentally revealed various types of pseudo-activities which manifest under conditions of formation and development of joint activity as specific psychological phenomenon that provide new possibilities for research and clarification of true sources of human's activity, including ones which clearly manifest as a form of various above norm activities or unclearly as a form of various distortions of the results of experimental laboratory studies of 'individual activity' of the test subject.

\section{Conceptual theory of ideation and the problem of giftedness}

The experimental studies revealed the mechanisms of formation and development of various types of pseudo-activities, which allowed to develop the concept of jointdialogical cognitive activity presenting new possibilities for studies and revelation of true sources of human's activity (Jakupov, 2012). Specific significance is presented by the potential possibilities of conceptual theory of ideation actualized in the concept of joint-dialogical cognitive activity (JDCA) and allows us to detect the missing component of the sequence of the problem analysis of abilities genesis along with giftedness. Examination of giftedness in the context of joint activity from the subject-subject relations point of view allows to understand the mechanisms of transformation of dispositions into the abilities.

Nowadays, there exist prevalent concepts and their modified variants describing essential secondary abilities which are represented as already possessed by the individual. This point of view misses the highly important factor of pseudo-joint activity, the necessity and possibility of which in the human ontogenesis was established in our experimental studies. This means that primary abilities - which are formed in the process of pseudo-joint activity are not accounted for. At the same time, they may be represented as certain 'stem abilities' determining the further development of various common and special abilities on their basis. In other words, if we want to understand the genesis of abilities and giftedness, we have to take into consideration the conditions of formation and development of 'stem abilities'.

The conceptual scheme of giftedness development is being developed by us in a form of specific intermediate result of the process of formation and development of abilities which allows to clarify many aspects of giftedness psychology which is considered as an unsolved problem by modern authors. Unsolved problems also include the problem of variability of 'age-dependent giftedness' (Leites, 2001), the 
problem of interconnection of giftedness and creative activity (Matyushkin, 1991), the problem of interconnection of psychic processes and abilities (Panov, 1998), etc.

The description of mechanisms of giftedness proposed by us allows to actualize its modern understanding as of systemic feature of developing human. This approach actualizes the role of ideation as system-forming factor of the system of cognitive processes itself, while the results of its functioning in certain social environment are fixed as the system of object's properties named as personality, individuality, giftedness.

The CIT's contribution into the research of giftedness is not only the vision of giftedness as intermediate results of pseudo-joint, joint, individual and pseudoindividual activities, but also the refinement of factors determining the psychological structure of giftedness.

\section{Ethnical prejudices as manifestation of conceptual barriers}

Ethnical prejudices as a specific form of manifestation of conceptual barriers may cause significant influence on the results of people's activity under conditions of polyethnic communication (Jakupov \& Nigay, 2005). The ethnical factor - while having great significance in the first days of communication - retreats to secondary positions in comparison with factors of group interaction which determine the effectiveness of joint activity and manifesting in the processes of transformation and alteration of ethnical prejudices.

Manifestation of ethnical peculiarities of interacting and communicating persons under conditions of joint cognitive activity is mainly conditioned by the subjective - conceptual contents of the common information fund. If the ethnical prejudices are mainly formed as a result of the process of inter - ethnical interaction itself, then the alterations of ethnical prejudices proceed as a result of sequential assumption by the students of various common funds of conceptual formations which accompany their interaction in subject - subject space of their ambient world.

Results of the analysis of the alteration of ethnical prejudices problem in the process of formation and development of students' cognitive activity allowed to formulate the following problems: firstly, does the mentioned technique influence the processes of formation and development of ethnical prejudices; secondly, will the intensification of barriers (conceptual and ethno-psychological) slow down the process of formation and development of joint-dialogical cognitive activity which proceed while manifesting on the behavioral level of the student's actions as a form of ethnical prejudices; thirdly, is the process of learning based on the technology of joint-dialogical cognitive activity which is able to facilitate more intensive alteration of the ethnical prejudices of the personality of students.

Purposely for solving the aforementioned problems there was performed experimental-empirical research, consisting of a study of ethnical prejudices arising under conditions of education modeled as a type of joint-dialogical cognitive activity.

In the context of known difficulties connected with revelation and measuring ethnical prejudices as a specific type of personal features which manifest in the 
process of communication and interaction of people under the conditions of polyethnic surroundings, the special experimental research test was developed. The main idea of this approach is modeling virtual mono-ethnic groups.

So, the results of experimental study of the process of alteration of ethnical prejudices in the process of formation and development of students' cognitive activity allow us to make following conclusions: firstly, the learning process, based on technology of joint-dialogical cognitive activity facilitates more intensive alteration of ethnical prejudices of students' personalities; secondly, there takes place an intensification of barriers (which are conceptual in their nature and ethno-psychological in their form) slowing down the process of formation and development of joint-dialogical cognitive activity process while manifesting on the behavioral level of the student's actions as a form of ethnical prejudices; thirdly, the technology of joint-dialogical cognitive activity does provide action on the processes of formation and development of ethnical prejudices; fourthly, method of modeling virtual mono-ethnic subgroups for studies of ethnical prejudices as specific manifestations of conceptual barriers in the process of formation and development of students' cognitive activity allows to overcome the experimental boundaries as the ethnopsychological method of research.

It is rather interesting to note that the latter aspect - which was firstly noted by W. Wundt - facilitated the great scientist in developing the idea of possibility and necessity of only two psychologies (by the end of his scientific career) - physiological psychology (he meant modern experimental psychology) and cultural psychology of nations, which is nowadays called ethno-psychology. Considering this historical fact, we can - presumably - speak of the method of modeling virtual mono-ethnic groups under the conditions of experimental research of ethno-psychological phenomena and its ability to overcome the Wundt's contraposition of experimental psychology and ethno-psychology.

\section{About mechanisms of psychotherapeutic impact}

We should assume that emotional state is actually a certain transitional form of emotional event (phenomenon) when the phenomenon ceased to be a process but hasn't yet become an attribute of human's personality. Remarkable feature of emotion as a certain state or condition is in the fact that it can easily transform into the process or into a feature, thus performing dynamical (tactical) regulation of activity in the first case and static (strategic) regulation of activity in the second case. The meaning of any psychotherapeutic intervention (psychotherapeutic impact) is in transformation of fixed properties (including emotional ones) of personality into states (including emotional states) and further into process (including emotional one).

Systemic psychological analysis of the educational process performed by us allows not only to systematize facts obtained by various researchers which state that personal changes in students are determined by the process of formation and development of their cognitive activity - but also to make a conclusion that its major form is joint-dialogical cognitive activity (Jakupov, 2012). This substantiated the following conclusion: if we desire to study changes in emotional field and personal traits of teachers in the process of their learning to regulate emotional states, then we must 
create all necessary conditions for formation and development of joint - dialogical cognitive activity.

We selected such forms of organization of the educational process which to the fullest extent facilitated formation and development of joint-dialogical cognitive activity (JDCA) of teachers. When teacher finds himself in the problem situation matching the JDCA type he presses forward to accomplishment of his goal - solving the problem. But requirements and norms concerning the means and methods of goal accomplishment which are proposed by the new activity make such teacher to reconstruct his behavior, making its new behavioral samples. New form of activity which stimulates the cognitive process and proceeds as a form of communicative interaction based on formation of 'common fund of conceptual formations' (Jakupov, 2012) causes re-thinking of its motivational \& axiological components, what can be empirically revealed in the changes of personal features of students. That means that the JDCA as a form of activity is based on its major psychological mechanism - conceptual interaction of participants - which facilitates changes, before all, in axiological \& motivational field of the personality, which corresponds with changes in the emotional field of personality.

Aforementioned facts firmly conform to the known empirical fact concluding that the effective psychological correction of human's personal features is performed under conditions of immersion into the social-psychological process of a group interaction. Studies in the framework of JDCA concept have demonstrated that this is possible along with optimal organization of the psychodynamical processes in such groups. In such case discrete fixed personal features (specific results of previous forms of subject's activity) undergo transformation, at first, into the state, mainly emotional in its contents, then into the process of self - cognition and comprehension of newly acquired personal features which, in turn, accomplishes as formation of new personal features. Psychological basis for all aforementioned transformations are the processes of goal formation, motivation formation and concept formation which assure formation, development and assumption of the common fund of conceptual formations by all participants of such groups.

In the proposed experimental model of special learning of emotional state regulation we outline three distinct types of regulation: current regulation, situational regulation and perspective regulation.

Under the framework of this model the dissertational study of T.A. Abdrasheetova was performed. It was centered on actual problem of small dynamics of conceptual formations of personality in young people with deviant behavior (addicted to psychoactive substances) in the process of psychological counseling (Abdrasheetova, 2008). The effectiveness of formation and transformation of conceptual formations of personality was substantiated in such a specially organized activity as joint - dialogical counseling (JDC) which realized conceptual approach and was based on the principles of development of joint - dialogical cognitive activity (JDCA) with the personality of counseled subject itself poses as the object of selfcognition. It was established that the dialogue (which is the technique of concept formation and concept - building) in the process of joint - dialogical counseling represents the main method of psychological impact possessing correcting and forming influence on the conceptual (personal) level of regulation of personality's vital activity. 
Conceptual ideation theory, while stimulating experimental studies in Kazakhstan concerning cognitive processes, possesses possibility to execute further development in numerous studies of cognitive activity and its problems - which is considered unite system of cognitive processes - with intellectual activity as the system-forming factor.

\section{References:}

Abdrasheetova, T.A. (2008). Dinamika smyslovykh obrazovaniy lichnosti v processe covmestnodialogicheskogo konsul'tirovaniya [Dynamics of conceptual formations of individuality in the process of joint-dialogical counselling] (Doctoral dissertation). Almaty.

Bogoyavlenskaya, D.B. (1986). Intellektual'naya aktivnost' kak problema tvorchestva [Intellectual activeness as a problem of creative work]. Rostov-on-Don: Rostov University Publishing.

Brushlinsky, A.V. (1982). Myshleniye kak process i problema deyatel'nosti [Ideation as a process and a problem of activity]. Voprosy psyhologii [Issues of psychology], 2, 28-40.

Jakupov, S.M. (1985). Tseleobrazovaniye v sovmestnoy deyatel'nosti [Formation of goals in joint activity] (Doctoral dissertation). Moscow.

Jakupov, S.M. (1992). Psikhologiya poznavatelinoy deyatel'nosti [Psychology of cognitive activity]. Alma-Ata: KazGU publishing.

Jakupov, S.M. (2012). Psychological structure of educational process: cognitive activity in educational process. Saarbrucken: LAP LAMBERT Academic Publising GmbH Co.

Jakupov, S.M., Nigay, N.V. (2005). Etnicheskiye predubezhdeniya kak proyavleniya smyslovykh bar'erov [Ethnical prejudices as manifestations of conceptual barriers]. Vestnik NAPK [NAPK Herald], 4, 5-15.

Leites, N.S. (2001). Vozrastnoy podkhod k detskoy odarennosti [Developmental approach to children's giftedness]. In V.I. Panov (Ed.). Odarennye deti: teoriya i praktika [Gifted children: theory and practice] (pp. 34-56).

Lomov, B.F. (1984). Metodologicheskiye i teoreticheskiye problem psikhologii [Methodological and theoretical problems in psychology]. Moscow.

Matyushkin, A.M. (1991). Razvitiye tvorcheskoy aktivnosti shkol'nikov [Development of creative activity of schoolchild]. Moscow: Prosveshenie.

Panov, V.I. (1998). Nekotorye teoreticheskiye i prakticheskiye problem odarennosti [Certain theoretical and practical problems of giftedness]. Prikladnaya psikhologiya [Applied psychology], 3, 28-39.

Petrovsky, V.A. (1975). K psikhologii aktivnosti lichnosti [About psychology of personality's activeness]. Voprosy psyhologii [Issues of psychology], 3, 26-38.

Ponomarev, Ya.A. (1981). Rol' neposredstvennogo obscheniya v reshenii zadach, trebuyushikh tvorcheskogo podkhoda [Role of direct communication in solving creative tasks]. In B.F. Lomov (Ed.). Problemy obsheniya $v$ psikhologii [Problems of communication in psychology] (pp. 79-91).

Vygotsky, L.S. (1982). Sobraniye sochineniy v 6 tomakh. Problemy obschey psikhologii [Collected works: 6 volumes. V.2. Problems of general psychology]. Moscow.

Vygotsky, L.S. (1983). Sobraniye sochineniy v 6 tomakh. Problemy razvitiya psikhiki [Collected works: 6 volumes. V.3. Problems of psychics' development. Moscow. 